\title{
Analisis Pendapatan Peternak Ayam Ras Pedaging dengan Sistem Kemitraan Berbeda di Kecamatan Tellusiattinge Kabupaten Bone
}

(Analysis of Broiler Breeders Income with Different Partnership System in Bone Regency,District Tellusiattinge)

\section{S. N. Sirajuddin, V. S Lestari dan M.Nizam}

\author{
Jurusan Sosial Ekonomi Fakultas Peternakan,Universitas Hasanuddin Mak \\ Makassar, 90245 Indonesia \\ e-mail : sitti nurani@yahoo.co.id, veronicasrilestari@yahoo.co.id,iccanknizam@yahoo.com
}

\begin{abstract}
This study aimed to determine differences income of broiler breeders on different partnership system. The research was conducted in the District Tellusiattinge March to May 2013 with the kind of research was descriptive and analytical data used was Revenue $=$ Revenue-Cost. The results showed that the income of broiler farmers who partner with companies was higher than farmers who partner with private companies (bakul)
\end{abstract}

Key words: income, partnership,breeders,broiler,company,privat company

\begin{abstract}
Abstrak
Penelitian ini bertujuan untuk mengetahui perbedaan pendapatan pendapatan peternak ayam ras pedaging pada sistem kemitraan berbeda. Penelitian ini dilakukan di Kecamatan Tellusiattinge pada bulan Maret hingga Mei 2013 dengan jenis penelitian adalah deskriptif dan analisis data yang digunakan yaitu Pendapatan= Penerimaan-Biaya. Hasil penelitian menunjukkan bahwa pendapatan peternak ayam ras pedaging yang bermitra dengan perusahaan lebih tinggi dibandingkan peternak yang bermitra dengan perusahaan perorangan(bakul)

Kata kunci: pendapatan,bermitra,peternak, ayam ras pedaging,perusahaan,bakul

\section{Pendahuluan}

Hasil analisis empirik agribisnis perunggasan peternakan broiler secara parsial yang dilakukan selama ini (Sumaryanto et al. 1989; Rusastra et al.,1990; Agustian dan Rachman, 1994; ; Saptana et al., 2002) memberikan beberapa informasi penting diantaranya bahwa struktur industri perunggasan perlu diarahkan pada penguatan konsolidasi kelembagaan di

tingkat peternak rakyat melalui pengembangan pola kemitraan dengan azas saling membutuhkan, saling memperkuat, dan saling menguntungkan Kemitraan inti-plasma dalam budidaya ayam pedaging merupakan suatu bentuk usaha peternakan yang dijalankan secara terorganisir dimana pihak perusahaan sebagai inti berfungsi menyediakan bibit(DOC), pakan,obat-obatan/vaksin serta pengaturan dan pengawasan
\end{abstract}


program produksi. Sedangkan peternak sebagai plasma berfungsi sebagai penyedia kandang, peralatan dan tenaga kerja (Sirajuddin,2010;Sirajuddin et al,2005).

Peternak plasma pada umumnya mempunyai ketergantungan yang tinggi kepada perusahaan inti dalam hal bibit(DOC), pakan dan input produksi lainnya. Selain itu terdapat beberapa kelemahan dan keterbatasan yang melekat pada peternak plasma diantaranya adalah terbatasnya modal, skill (penguasaan teknis), akses pasar dan lemahnya kemampuan memprediksi pasar yang sangat fluktuatif setiap saat. Kondisi ini menyebabkan peternak plasma dalam posisi yang lemah terutama dalam posisi tawar terhadap harga DOC, pakan ternak dan harga ayam yang dihasilkan. Dengan posisi yang lemah ini, daya tawar peternak plasma lebih banyak ditentukan oleh perusahaan inti termasuk dalam pembagian laba dalam pola kemitraan ayam ras pedaging sehingga terjadinya distribusi laba yang kurang seimbang antara inti dan plasma sangat dimungkinkan (Windarsari,2007). Kemitraan melibatkan antara pihak inti (perusahaan) dan pihak plasma (peternak) dengan menyepakati kontrak yang ditawarkan oleh perusahaan.

Kontrak kemitraan ayam ras pedaging dilakukan antara pihak perusahaan sebagai inti dengan pihak peternak atau petani/peternak. Pihak inti adalah perusahaan terintegrasi yang menyiapkan seluruh sarana produksi mulai dari bibit ayam (DOC), pakan, obat-obatan serta asistensi budidaya. Pihak peternak menyiapkan sarana kandang, peralatan ternak serta tenaga kerja (Sirajuddin dkk.,2012:Sirajuddin,dkk.,2007).

Pada wilayah Sulawesi Selatan akan lebih mudah kita untuk menemukan peternakan ayam ras pedaging yang merupakan plasma pada perusahaan inti dibandingkan peternak dengan usaha mandiri. Hal tersebut dikarenakan kemitraan di Sulawesi Selatan tergolong mengalami perkembangan yang cukup pesat dan menjadi sebaliknya untuk peternak yang berusaha mandiri. Kemitraan usaha ayam pedaging telah berkembang pesat di Indonesia, hal ini memberikan keuntungan yang cukup tinggi bagi peternak. Hal tersebut didukung oleh kutipan pada majalah Poultry Indonesia berdasarkan informasi yang diperoleh dari Dinas Peternakan dan Kesehatan Hewan, Sulawesi Selatan, bahwa hingga saat ini jumlah kelompok mitra petani ternak ada sebanyak 1.200 orang dan perusahaan inti industri perunggasan sebanyak 24 perusahaan (Hatta, 2012 dalam Surya,2013).

Peternak yang memelihara ayam ras pedaging di Kecamatan Tellusiattinge bekerja sama dengan beberapa perusahaan kemitraan, namun pada daerah tersebut juga terdapat peternak yang tidak bermitra dengan perusahaan sebagaimana peternak kebanyakan. Peternak yang dimaksud juga bukan peternak yang mandiri melainkan peternak yang melakukan kerjasama dengan pedagang pengumpul (bakul) atau kemitraan perseorangan.hal ini sesuai hasil penelitian Supriyatna, $\operatorname{dkk}(2006)$ 
bahwa peternak pola kemitraan melalui inti memiliki akses langsung ke pasar modern dan konvensional sementara peternak mandiri umumnya melakukan penjualan melalui pedagang pengumpul. Keterkaitan fungsional yang Bentuk kerjasama peternak dengan kemitraan perseorangan(bakul) ini merupakan pola yang telah dilakukan peternak lokal sebelum konsep kemitraan perusahaan diperkenalkan oleh perusahaan-perusahaan mitra kira-kira dimulai tahun 1997, sedangkan keberadaan perusahaan-perusahaan kemitraan menurut masyarakat setempat diperkirakan pada awal tahun 2003. Sejak masuknya kemitraan berangsur-angsur peternak beralih untuk bermitra dengan perusahaanperusahaan tersebut sehingga peternak yang menggunakan kerjasama dengan kemitraan perseorangan ini semakin berkurang.

\section{Metode Penelitian}

Penelitian ini dilaksanakan selama kurang lebih 2 bulan yaitu pada bulan Maret sampai dengan bulan Mei 2013 di Kecamatan Tellusiattinge, Kabupaten Bone, Sulawesi Selatan. Penentuan lokasi tersebut diambil karena adanya dua bentuk kerjasama yang berbeda di kecamatan tersebut yaitu kerjasama dengan kemitraan perseorangan (bakul) dan kerjasama dengan perusahaan kemitraan mitra jaya mandiri(MJM).

Jenis penelitian ini adalah deskriptif yaitu menggambarkan atau menguraikan variable penelitian yaitu pendapatan usaha peternakan ayam ras pedaging yang bekerjasama dengan kemitraan perseorangan (bakul) dan yang bekerjasama dengan perusahaan di Kecamatan Tellusiattinge, Kab. Bone.

Populasi merupakan peternak ayam ras pedaging yang bekerjasama dengan kemitraan perseorangan (bakul) dan peternak yang bermitra dengan perusahaan sedangkan untuk sampel yang digunakan sekaligus merupakan keseluruhan dari jumlah populasi, hal tersebut dikarenakan jumlahnya yang cukup kecil. Khusus pengambilan sampel untuk peternak yang bermitra dengan perusahaan yaitu memiliki populasi 1500 ekor dimaksudkan agar meminimalisir pembiasan dalam melakukan perbandingan dengan pola kerjasma antara peternak dengan kemitraan perseorangan (bakul) yang memiliki populasi maksimal 500 ekor.

Metode pengumpulan data yang dilakukan pada penelitian ini adalah observasi dan wawancara sedangkan jenis data yang digunakan yaitu data kuantitatif yaitu data yang berupa angka-angka berdasarkan hasil kuisioner dari hasil usaha ayam ras pedaging meliputi jumlah penjualan ayam, feses, dan karung pakan serta biaya-biaya di Kecamatan Tellusiattinge Kabupaten Bone.

Adapun sumber data yang digunakan pada penelitian ini adalah data primer yaitu data yang bersumber dari hasil wawancara langsung dengan peternak meliputi identitas responden, hasil usaha dan biaya-biaya dan data sekunder yaitu data yang diperoleh dari instansi-instansi terkait, Kantor Kecamatan Tellusiattinge dan lain sebagainya yang telah tersedia, seperti gambaran umum lokasi, keadaan 
kondisi wilayah, kependudukan dan sejarah singkat dan lain sebagainya.

\section{Analisa Data}

Analisis data yang digunakan pada penelitian ini yaitu analisa statistik deskriptif yaitu dengan menghitung rata - rata pendapatan, persentase, menghitung besarnya sampel dan melakukan penyederhanaan data serta penyajian data dengan menggunakan tabel. Untuk mengetahui seberapa besar pendapatan peternak dari usaha ayam ras pedaging digunakan rumus menurut Soekartawi (2006) :Pd = TR TC

$$
\begin{aligned}
\text { Yaitu } & \text { Pd }=\text { Total Pendapatan }(\mathrm{Rp}) \\
\text { TR } & =\text { Total Penerimaan }(\mathrm{Rp}) \\
\text { TC } & =\text { Total Biaya }(\mathrm{Rp})
\end{aligned}
$$

\section{Hasil dan Pembahasan}

\section{Biaya Total (TC)}

Biaya total (TC) adalah merupakan penjumlahan dari biaya variabel (bibit, pakan, vaksin/obatobatan, air dan listrik) dengan biaya tetap (penyusutan peralatan, penyusutan kandang, dan pajak bumi bangunan (PBB). Adapun biaya total produksi yang dikeluarkan oleh peternak di Kecamatan Tellusiattinge, Kabupaten Bone dapat dilihat pada Tabel 1.

Tabel 1 menunjukkan dari total biaya produksi tersebut biaya variabel merupakan biaya yang paling besar dikeluarkan oleh peternak dalam masa satu periode produksi dibandingkan dengan biaya tetap. Biaya variabel merupakan komponen biaya terbesar karena berkaitan dengan jumlah skala usaha atau jumlah ternak yang dipelihara peternak dimana semakin tinggi jumlah ternak makin tinggi juga biaya variabel yang dikeluarkan

\section{Penerimaan Hasil Produksi}

Total penerimaan merupakan penjumlahan komponen penerimaan hasil produksi dinyatakan dalam bentuk rupiah yaitu penjualan daging/ayam, penjualan feses dan penjualan karung pakan. Adapun total penerimaan yang didapatkan peternak di Kecamatan Tellusiattinge Kabupaten Bone dapat dilihat pada Tabel 2.

Tabel 2 menunjukkan bahwa total penerimaan dari semua komponen yang bermitra dengan perusahaan perseorangan pada skala usaha 500 yakni Rp.13.014.500 sedangkan pada skala usaha 1.000 total penerimaannya adalah Rp.24.001.000 sedangkan yang bermitra dengan perusahaan total penerimaannya adalah Rp. 34.257.000. Berdasarkan tabel tersebut juga menunjukkan komponen penerimaan usaha peternakan ayam broiler di Kecamatan Tellusiattinge Kabupaten Bone yaitu bersumber dari hasil penjualan daging/ayam, penjualan feses dan penjualan karung pakan. Dari tabel tersebut juga dilihat sumber penerimaan daging/ayam yang paling besar memperoleh penerimaan adalah dari penjualan daging/ayam.

\section{Pendapatan Peternak}

Pendapatan atau keuntungan merupakan tujuan setiap jenis usaha. Keuntungan dapat dicapai jika jumlah penerimaan yang diperoleh dari hasil 
Tabel 1. Biaya Total yang Bermitra dengan Perusahaan Perseorangan (Bakul) di Kecamatan Tellusiattinge Kabupaten Bone

\begin{tabular}{|c|c|c|c|c|c|}
\hline No & $\begin{array}{c}\text { Jenis } \\
\text { Kemitraan }\end{array}$ & $\begin{array}{c}\text { Skala } \\
\text { Usaha } \\
\text { (Ekor) }\end{array}$ & $\begin{array}{c}\text { Total Biaya } \\
\text { Tetap } \\
\text { (Rp/Periode) }\end{array}$ & $\begin{array}{c}\text { Total Biaya } \\
\text { Variabel } \\
\text { (Rp/Periode) }\end{array}$ & $\begin{array}{c}\text { Total Biaya } \\
\text { (Rp/Periode) }\end{array}$ \\
\hline 1. & $\begin{array}{c}\text { Kemitraan } \\
\text { Perseorang } \\
\text { an (bakul) }\end{array}$ & 500 & $244.541,67$ & 11.680 .000 & $11.924 .541,67$ \\
\cline { 3 - 6 } & 1.000 & 715.450 & 20.949 .000 & 21.664 .450 \\
\hline 2. & $\begin{array}{c}\text { Kemitraan } \\
\text { Perusahaan }\end{array}$ & 1.500 & $1.262 .434,27$ & 28.969 .800 & $30.231 .436,27$ \\
\hline
\end{tabular}

Sumber: Data Primer yang telah Diolah. 2013

| Tabel 2. Total Penerimaan Peternak pada Pola Kemitraan yang Berbeda di Kecamatan Tellusiattinge Kabupaten Bone

\begin{tabular}{|c|c|c|c|c|c|c|}
\hline \multirow[b]{2}{*}{ No } & \multirow{2}{*}{$\begin{array}{c}\text { Jenis } \\
\text { Kemitraan }\end{array}$} & \multirow{2}{*}{$\begin{array}{l}\text { Skala } \\
\text { Usaha } \\
\text { (Ekor) }\end{array}$} & \multicolumn{3}{|c|}{ Sumber Penerimaan(Rp) } & \multirow{2}{*}{$\begin{array}{l}\text { Total } \\
\text { (Rp) }\end{array}$} \\
\hline & & & Daging/ayam & Feses & $\begin{array}{c}\text { Karung } \\
\text { Pakan }\end{array}$ & \\
\hline \multirow[t]{2}{*}{1.} & \multirow{2}{*}{$\begin{array}{l}\text { Kemitraan } \\
\text { Perseorang } \\
\text { an (bakul) }\end{array}$} & 500 & 12.849 .500 & $\begin{array}{c}100.0 \\
00\end{array}$ & 65.000 & 13.014500 \\
\hline & & 1.000 & 23.668 .500 & $\begin{array}{c}220.0 \\
00\end{array}$ & 112.500 & 24.001000 \\
\hline 2. & $\begin{array}{c}\text { Kemitraan } \\
\text { Perusahaa } \\
\text { n }\end{array}$ & 1.500 & 33.740 .000 & $\begin{array}{c}310.0 \\
00\end{array}$ & 207.500 & 34.257000 \\
\hline
\end{tabular}

Sumber: Data Primer yang telah Diolah. 2013

Tabel 3. Total Pendapatan Peternak pada Pola Kemitraan yang Berbeda di Kecamatan Tellusiattinge Kabupaten Bone

\begin{tabular}{|c|c|c|c|c|c|c|}
\hline No & $\begin{array}{c}\text { Jenis } \\
\text { Kemitraan }\end{array}$ & $\begin{array}{c}\text { Skala } \\
\text { Usaha } \\
\text { (Ekor) }\end{array}$ & $\begin{array}{c}\text { Total } \\
\text { Penerimaan } \\
\text { (TR) } \\
\text { (Rp/Periode) }\end{array}$ & $\begin{array}{c}\text { Total Biaya } \\
\text { (TC) } \\
\text { (Rp/Periode) }\end{array}$ & $\begin{array}{c}\text { Total Pendapatan } \\
\text { (Pd) } \\
\text { (Rp/Periode) }\end{array}$ & $\begin{array}{c}\text { Total } \\
\text { Pendapatan } \\
\text { (pd) } \\
\text { (Rp/ekor) }\end{array}$ \\
\hline 1. & $\begin{array}{c}\text { Kemitraan } \\
\text { Perseorang } \\
\text { an (bakul) }\end{array}$ & 1.000 & 24.001 .000 & 21.664 .450 & 2.336 .550 & $2.336,55$ \\
\hline 2. & $\begin{array}{c}\text { Kemitraan } \\
\text { Perusahaa } \\
n\end{array}$ & 1.500 & 34.257 .500 & $30.231 .436,27$ & $4.026063,73$ & $2.684,04$ \\
\hline
\end{tabular}

Sumber: Data Primer yang telah Diolah. 2013 
usaha lebih besar daripada jumlah pengeluarannya. Semaking tinggi selisih tersebut, semaking meningkat keuntungan yang dapat diperoleh. Bisa diartikan pula bahwa secara ekonomi

tidak layak dilanjutkan. Adapun besarnya pendapatan peternak di Kecamatan Tellusiattinge Kabupaten Bone dapat dilihat pada Tabel 3

Berdasarkan data pada tabel 3 bahwa pendapatan peternak yang bermitra dengan perusahaan perseorangan (bakul) pada skala usaha 500 sebesar Rp.1.089.958,33/periode atau Rp.2.179,91/ekor dan pada skala 1.000 sebesar Rp. 2.336.550/periode atau pendapatan Rp.2.336,55/ekor sedangkan pendapatan peternak yang bermitra dengan perusahaan dengan skala usaha 1.500 sebesar Rp.4.026.063,73/periodenya atau ratarata Rp.2.684,04/ekor

Hal ini ini sejalan dengan pendapat Gusasi dan Saade (2006) bahwa perbedaan pendapatan pada setiap tingkatan skala usaha sangat nyata sehingga manfaat dan keuntungan dapat diperoleh pada skala usaha yang lebih besar.

\section{Kesimpulan dan Saran}

\section{Kesimpulan}

Dari hasil dan pembahasan yang telah dilakukan maka dapat ditarik kesimpulan yaitu pendapatan peternak yang bermitra dengan perusahaan cenderung lebih tinggi dibandingkan pendapatan peternak yang bermitra dengan kemitraan perseorangan (bakul).

\section{Saran}

usaha tersebut layak dipertahankan atau dilanjutkan. Jika situasinya terbalik, usaha tersebut mengalami kerugian dan secara ekonomis sudah

Peternak yang mengikuti kemitraan perseorangan (bakul) agar dapat mempertimbangkan tawaran kemitraan oleh perusahaan yang berdasarkan pola dan pendapatannya lebih menguntungkan.

\section{Daftar Pustaka}

Agutian, A. dan B. Rahman. 1994. Aspek Penyaluran Sapronak, Pemasaran Hasil dan Pola Kerjasama dalam PIR Perunggasan di Jawa Barat dan Jawa Timur. Forum Penelitian Agro Ekonomi 12(2). Puslitbang Sosek Pertanian, Bogor.

Gusasi. A dan Saade. M.A 2006. Analisis Pendapatan dan Efisiensi Ternak Ayam Potong pada Skala Usaha Kecil. Jurnal Agri sistem. 2 (1):1-7

Rusastra, I.W.R., Y.Yusdja dan Sumaryanto. 1990. Analisis Kelembagaan Perusahaan Inti Rakyat Perunggasan Nasional. Forum Penelitian Agro Ekonomi 8(1). Puslitbang Sosek Pertanian, Bogor. 
Saptana, R. Sayuti dan K.M.

Noekman. 2002. Industri

Perunggasan: Memadukan

Pertumbuhan dan

Pemerataan. Forum Penelitian

Agro Ekonomi 20(1).

Puslitbang Sosek Pertanian, Bogor.

Sirajuddin, S.N, Aminawar, M, Yunus, D. 2007. Faktor-faktor yang Memotivasi Peternak dalam Melakukan Kemitraan di Kecamatan Bantimurung, Kabupaten Maros. Jurnal Agribisnis,.VI(2) :14-27.

Sirajuddin, S.N,.Rohani, S, Lestari, V.S, Aminawar, M, Siregar A.R, Aryanto. 2012. Penerapan Kontrak Sistem Kemitraan Dalam Menunjang Agribinis Ayam Ras Pedaging di Propinsi Sulawesi Selatan. Seminar Nasional Peternakan Berkelanjutan 4. Prosiding. Hal.238-240.

Sirajuddin,S.N. 2005. Analisis Produktifitas Kerja Peternak pada Usaha Ayam Ras Pedaging Pola Kemitraan dan Mandiri di Kabupaten Maros. Jurnal Ilmu dan Teknologi Peternakan UNHAS . VI (2):151-159

Sirajuddin, S.N. 2010. Sistem Bagi Hasil pada Peternak Ayam Pedaging Pola Kemitraan di Kabupaten Gowa, Provinsi Sulawesi Selatan. Jurnal Agribisnis. VII (2)

Supriyatna,S.,Wahyuni,S.,Rusastra.I.W .R.2006.Analisis Kelembagaan Kemitraan Usaha Ternak Ayam Ras Pedaging:Studi Kasus di Propinsi Bali.Seminar Nasional Teknologi dan Peternakan.hal :830-840

Surya,A. 2013. Pengambilan Keputusan Peternak Ayam Ras Pedaging Dalam Menentukan Perusahaan Mitra. Skripsi. Jurusan Sosial Ekonomi Fakultas Peternakan UNHAS

Windarsari. 2007. Kajian Usaha Peternakan Ayam Ras Pedaging di Kabupaten Karanganyar: Membandingkan antara Pola Kemitraan dan Pola Mandiri. Tesis. Sekolah Pascasarjana Institut Pertanian Bogor, Bogor. 